\title{
¿DEBE SER LA MORAL EL ÚNICO CRITERIO PARA LEGISLAR? ${ }^{1}$
}

os problemas de la relación entre la moral y el derecho pueden enfocarse desde perspectivas muy diferentes ${ }^{2}$. Voy a tratar de estudiarla desde una perspectiva inusual como es el caso de la ciencia de la legislación. Defenderé la idea de que desde el punto de vista de los nuevos instrumentos jurídicos -es decir, la legislación en un sentido muy amplio- la intuición de la moralidad no debe ocupar el papel predominante que hoy ocupa y que a la justificación de la excelencia moral puede y debe añadirse otros criterios importantes.

Los juristas muchas veces tienen no sólo que aplicar el derecho sino diseñar y redactar leyes, reglamentos y contratos. Participan activamente en la creación de nuevos instrumentos jurídicos. Voy a estudiar si usan algún modelo teórico subyacente a esa actividad. En otras palabras, en las facultades de derecho y en la enseñanza jurídica en general ¿ocupa algún lugar el diseño legislativo?, ¿qué es lo que sabemos sobre este tema como juristas profesionales?

Sugeriré que carecemos de modelos. Los juristas con experiencia profesional saben intuitivamente cómo se debe diseñar un documento jurídico pero carecen de un modelo racionalizador. En otras palabras: no tienen un esquema racional de diseño legislativo.

En primer lugar, voy a explicar por qué no existe una ciencia y una técnica legislativa en la cultura jurídica continental hasta épocas muy recientes. En segundo lugar, sugeriré por qué son necesarias

${ }^{1}$ Este trabajo se ha beneficiado de la ayuda n. PB 900327 y la beca 92/39 que la Dirección General de Investigación Científica y Técnica ha concedido al equipo de la Universidad Pompeu Fabra.

${ }^{2}$ Véase E. Garzón Valdés Algo más acerca de la relación entre derecho y moral en Doxa 8. pág. 111. Véase también los trabajos de F. Laporta, A. Peczenick y R. Silhala en el mismo número. 
estas disciplinas en el Estado intervencionista y, por último, trataré de proponer un conjunto de preguntas que debería formularse quien diseña un nuevo documento jurídico que puede constituir un modelo rudimentario de cómo legislar. Pienso que la propuesta exige superar limitaciones del punto de vista tradicional y apunta a cuestiones que tienen importancia teórica y práctica.

Mi propuesta se separará de la concepción dominante que sostiene una vinculación estricta entre la nueva legislación y un modelo ético determinado. Sugiere que la tarea legislativa no es una mera cuestión de voluntad y de excelencia ética. Un buen legislador no es el que proclama ideales excelentes, sino el que los consigue.

En la literatura castellana se han producido trabajos pioneros de ciencia de la legislación y técnica legislativa. Entre ellos cabe destacar los del grupo GRETEL y especialmente los de Manuel Atienza $a^{3}$ en los que me he inspirado. Pero, como veremos, estas disciplinas todavía están en un nivel muy primitivo y convendría dedicar atención a ellas no sólo por el interés teórico, sino también por sus consecuencias prácticas.

\section{El modelo de Estado liberal y la tarea legislativa}

En las facultades de derecho se enseña a pensar como un jurista. Eso significa que el estudioso utilizará la red conceptual jurídica y desde ella analizará los problemas que se le plantean. Ahora bien, el modelo de derecho ideal es el liberal. Las categorías jurídicas básicas están construidas desde los presupuestos liberales. En ese modelo la función del jurista está subordinada al derecho. El juez es el encargado de hacer cumplir las leyes. La subordinación a la ley y al derecho es uno de sus presupuestos básicos que se manifiesta tanto en el científico del derecho que describe normas como en el operador jurídico que las aplica.

La función del Estado se limita a la actividad de garantizar el orden público. Para conseguir este objetivo es suficiente la creación de normas y su aplicación a los casos de conductas desviantes. El propio Estado se limita en principio a la actividad de garantizar el orden público. Para conseguir este objetivo es suficiente el diseño de normas y su aplicación. El Estado no tiene otras actividades y en el caso de que las tuviera implicaría una perversión del modelo ideal, una perversión que como tal debería eliminarse. En síntesis, la actividad del Estado es de creación o aplicación del derecho.

${ }^{3}$ El modelo de diseño sigue -con algunas variantes- el propuesto por Atienza en diversas publicaciones. Véase por ejemplo su trabajo Ciencia de la Legislación y Sociología en R. Bergali ed. El derecho y sus realidades. PPU, Barcelona y su ponencia presentada en el Congreso de la IVR en Gottingen 1991. 
Es fácil darse cuenta que -idealmente- la tarea del jurista se inicia donde ha concluido el legislador. La subordinación a la ley supone que el jurista no diseña leyes, sino que las aplica o las conoce. Si ahora nos preguntamos cómo es posible que no tengamos ideas claras y distintas acerca de cómo se debe legislar, la respuesta desde la perspectiva de la red conceptual jurídica es sencilla y coherente: No es asunto de los juristas. La ciencia de la Legislación es el feudo de los políticos o de los filósofos. Los juristas no tratan de proponer cómo debe ser el derecho sino que deben aplicar -y en su caso describir- el derecho tal y como ha sido establecido por el legislador.

En el modelo de Estado de derecho liberal la función del jurista estaba claramente definida. Existía una separación radical entre la creación y la aplicación del derecho. El jurista es el especialista del momento aplicativo del derecho y su conocimiento iba dirigido a resolver los problemas interpretativos y de aplicación.

\section{El modelo de ciencia jurídica}

La ciencia jurídica de la época responde también a ese planteamiento. Un buen ejemplo de cómo se debe hacer ciencia jurídica lo tenemos en Austin. Este autor sostuvo que una ciencia completa del derecho debía tratar dos problemas fundamentales. Por una parte la Ciencia de la Legislación se ocupaba de cómo debe ser el derecho. La Ciencia de la Legislación es una disciplina prescriptiva y sus cultivadores fueron los políticos y filósofos. Junto a la Ciencia de la Legislación existía otra disciplina -la Jurisprudencia- cuyo objeto era la descripción del derecho positivo. La Jurisprudencia responde a la cuestión cómo es el derecho. Ésta es la disciplina típicamente jurídica cultivada por los juristas. El paradigma positivista no sólo exigió la distinción entre las disciplinas, sino que sostuvo que no existían puentes entre la Jurisprudencia y la Ciencia de la Legislación. Para describir el derecho no es necesario saber cómo debe ser. La ciencia jurídica debe limitarse a la descripción del derecho positivo prescindiendo de los juicios de valor. La ciencia jurídica debe ser neutral y por tanto independiente de los intereses políticos. El único puente de comunicación va de la Jurisprudencia a la Ciencia de la Legislación pues para saber cómo debe ser el derecho es preciso reunir información sobre el derecho positivo.

Sin embargo, los filósofos y políticos no han tenido muy en cuenta esta limitación, ya que la mayoría de los proyectos de una sociedad mejor se dibujan en hojas en blanco sin tener en cuenta cómo es la sociedad y el derecho actual. En este sentido la mayoría de las filosofías políticas son utópicas. El punto de vista de Austin y 
de sus seguidores supone que el derecho es un producto acabado y que el científico del derecho tiene un objetivo fundamental: Describir y explicar ese derecho. El científico es un descriptor de ese producto. Las teorías jurídicas de Kelsen y Hart están en esa línea y constituyen las versiones más sofisticadas del paradigma austiniano.

La tarea de la ciencia acaba ahí. Desde el punto de vista de la justificación de las decisiones el científico poco tiene que decir. Sin embargo, en esa época se consideraba que la tarea de interpretar era cognoscitiva y no decisoria. El juez justifica sus decisiones en las normas y su tarea -como ya hemos visto- era aplicadora de derecho. El modelo silogístico de aplicación del derecho responde a este punto de vista. Pero nunca quedó claro cómo de la descripción del derecho se podía pasar al campo de la justificación.

\section{Adecuación del modelo a la sociedad}

Sin duda ese modelo se construyó sobre la base de un Estado que pretendía limitarse a la garantía del orden público y que presuponía que las leyes naturales de la oferta y la demanda producían -conducidas por la mano invisible- unos resultados inmejorables. La función del Estado era garantizar el buen funcionamiento de la libertad de iniciativa y de la propiedad.

Ese modelo produjo también una cultura administrativa determinada. Los funcionarios públicos tienen la misión de cumplir y aplicar la ley. El juridicismo es la cultura administrativa dominante. La administración pública debe estar subordinada a la ley y al derecho. Los funcionarios no tienen actividades de gestión, sino simplemente su obligación consiste en aplicar el derecho. Cumpliendo con el derecho agotan su función. Las doctrinas menos liberales aducían la potestas imperium de la administración y trataban de reducir la responsabilidad de la administración, pero en todo caso la dominancia se encuentra en este punto de vista liberal.

El modelo es coherente aunque sus realizaciones prácticas no ofrecen resultados que lo confirmen. No es cierto que en realidad histórica la función exclusiva de los juristas fuera aplicar el derecho, ni que la jurisprudencia fuera meramente descriptiva ni que la función del Estado excluyera intervenciones en la sociedad a través de actividades de fomento o de protecciones de determinadas actividades económicas y sociales.

\section{La Constatación de la crisis}

Los valores liberales continúan vigentes en nuestra sociedad. Los derechos y libertades ocupan un lugar importante en 
el diseño y justificación de las sociedades actuales. Y, sin embargo, nuestras sociedades no pueden ser calificadas de liberales.

El advenimiento del Estado del bienestar ha supuesto profundas transformaciones en los modelos ideales de justificación. La mano invisible y la racionalidad individual son incapaces de generar bienes públicos. Las quiebras del mercado exigen la intervención del Estado. La economía de mercado no ofrece el mejor de los mundos posibles. El mundo real no es el mundo ideal de la competencia perfecta y la analogía entre mundo ideal y real es demasiado precipitada. Conviene pues analizar con cuidado los cambios que se han producido. En primer lugar la conciencia de que existen quiebras del mercado invalidan el dogmatismo de la mano invisible. Un ejemplo ilustrativo es el dilema del prisionero.

Creo que es importante aducir este argumento porque tras la crisis del socialismo se sostiene acríticamente el dogmatismo de la eficiencia del mercado. En síntesis hay situaciones en las cuales la eficiencia no se produce dejando la libre circulación del mercado, sino que se precisa intervención estatal. Por otra parte tampoco se puede inferir que cualquier intervención del Estado en caso de quiebra del mercado produzca necesariamente la eficiencia. Los mecanismos correctores intervencionistas también pueden distorsionar y producir ineficiencias. Conviene tener muy presente esta idea, pues cuando tratemos del problema de cómo legislar el concepto de eficiencia jugará un papel muy importante.

La proliferación del intervencionismo estatal, justificable o no, ha producido un cambio muy fundamental de sus actividades. La función del Estado ya no es sólo garantizar el orden público sino que interviene directamente en la economía y en la sociedad gestionando directamente servicios públicos, creando y dotando a los países de infraestructura necesaria y abarcando poco a poco muchas actividades que tradicionalmente correspondían a la sociedad civil.

La adaptación de la administración a estos cambios ha sido insuficiente y ha generado una inadecuación institucional y personal de gran magnitud. La reforma de la administración exige cambios sustanciales en la cultura administrativa dominante. En otras palabras, el estado del bienestar necesita otro tipo de juristas. Juristas que piensen con redes conceptuales distintas a las liberales. Necesita también sistemas de resolución de conflictos que no sólo tengan en cuenta quién tiene derecho, sino las consecuencias distributivas, de coste y de implementación. El modelo kelseniano de funcionario público que aplica el derecho (y que no distingue entre funcionario de la administración y juez) es inadecuado en el Estado intervencionista. 


\section{La cultura administrativa liberal}

Es bien conocida la inadecuación institucional y personal de la administración y los intentos frustrados de su reforma. El diagnóstico está claro. La administración del estado del bienestar es inadecuada porque sostiene una cultura administrativa fundamentalmente jurídica. Se da por descontado que la administración cumple su función si se limita a aplicar el derecho. El cumplimiento formal de la legalidad es el elemento fundamental a la hora de enjuiciar la actividad de los funcionarios. Las tareas de gestión no son valoradas por los resultados o por el alcance de los objetivos. Los criterios de juicio son los tradicionales. Pero su función es muy distinta y requiere criterios distintos, un cambio de mentalidad y el diseño institucional adecuado.

\section{Los valores de la nueva cultura administrativa}

La administración de un estado intervencionista no se puede justificar única y exclusivamente por el cumplimiento de la ley. En primer lugar se debería destacar que la administración se concibe como una institución prestadora de servicios y el administrado deja de estar sometido a la potestad de la administración para transformarse en un usuario. La soberanía del usuario exige una responsabilidad más directa por parte de la administración. Desde el punto de vista del servicio público la superioridad de la administración carece de justificación.

Un segundo punto muy importante es la variación en el criterio de juicio. Una administración intervencionista debe unir a los valores de la legalidad los de la eficacia y la eficiencia. La asignación de recursos debe ser la correcta y alcanzar los objetivos ocupa un lugar muy importante a la hora de enjuiciar el conjunto de la actividad estatal. Lo importante de un servicio público es que sea además de legal, eficiente, eficaz y oportuno.

He hablado de la inadecuación institucional, pero conviene hablar también de la inadecuación personal. Por supuesto que en la formación y selección del funcionariado se inculca una cultura en la cual cumplir con los objetivos y asignar correctamente los recursos ocupa un lugar subordinado. La mentalidad es inadecuada.

Hoy la sociedad necesita funcionarios imbuidos de la nueva cultura administrativa en la cual al cumplimiento de la legalidad se le añaden la eficacia y la eficiencia. Una sociedad que despilfarra recursos es una sociedad mal diseñada. Un funcionario debe ser juzgado no sólo por el cumplimiento de la ley, sino también por la asignación óptima de los recursos. 
Hasta aquí he aludido a un conjunto de problemas sobre la crisis de la administración que explican por qué las tareas creativas, las de gestión y las de diseño no ocupan el lugar relevante que merecerían. La red conceptual liberal es incapaz de ofrecer una buena perspectiva del problema. Tampoco es capaz de ofrecer criterios normativos poderosos.

Las instituciones de enseñanza no han reaccionado hasta épocas muy tardías y, probablemente el éxito y la proliferación de los masters se deba a la promesa -a veces engañosa- de una formación específica necesaria para cumplir con determinados objetivos.

A la inadecuación personal e institucional debería añadirse la educativa. El modelo liberal continúa ejerciendo una influencia muy poderosa y, sin embargo, las necesidades de la sociedad actual son diferentes.

Este conjunto de razones explican por qué no se ha desarrollado una técnica ni una ciencia legislativa. La nueva cultura jurídica exige no sólo la aplicación de criterios ya establecidos, sino también la creación de nuevos criterios de juicio.

\section{La tarea legislativa}

Junto a estos problemas nos encontramos con otro elemento muy importante: La concepción de cómo se debe legislar está ligada a concepciones éticas y políticas determinadas. Pero éstos no son los únicos elementos que deben tenerse en cuenta si se desea diseñar leyes bien hechas.

El avance de las ciencias sociales y especialmente la aplicación de la teoría de los juegos al conocimiento social han puesto de manifiesto que la tarea de dirigir el comportamiento de la gente no es meramente una cuestión de voluntad y de objetivos éticos. El mundo no se cambia a golpe de decreto. A la idea directora de una racionalidad individual que produce -por agregación- una racionalidad colectiva se le opone la especificidad de la racionalidad colectiva o bien la ausencia de la racionalidad colectiva. Estos planteamientos tienen consecuencias importantes a la hora de conceptualizar cómo se debe diseñar un instrumento jurídico. Quizá a la imagen de un mundo que cambia merced a la voluntad del legislador cabría oponer la de una decisión voluntaria que se sumerge en un mundo de interacciones que no se sabe exactamente, ni se puede saber, a dónde conducirá.

Uno de los grandes descubrimientos de las ciencias sociales recientes -si es que se puede hablar de ello- ha sido el estudio de las consecuencias no intencionadas de las acciones individuales. Este punto de vista entusiasmó a los economistas clásicos del siglo 
XVIII y ha penetrado en el corazón mismo de la mayoría de las ciencias sociales. La mano invisible de A. Smith es un buen ejemplo de esa idea. El dilema del prisionero es otro y de signo contrario.

Se acabó la vieja creencia en el cambio por el diseño de instituciones y cada día se es más consciente de la dificultad de prever las consecuencias de cualquier modificación voluntaria del mundo. La irrupción de una avalancha de estudios que explotan el filón de las consecuencias involuntarias ha puesto en entredicho el paradigma voluntarista y ha supuesto fuertes limitaciones a los cálculos de consecuencias. Hoy no es tan fácil ser legislador consecuencialista como en las épocas del auge del voluntarismo.

Ese es el fin de la idea de un legislador omnisciente y omnipotente. La idea del aprendiz de brujo -que desencadena voluntariamente un conjunto de consecuencias que no puede controlar- se acerca más a la realidad que la del semidiós que mediante su voluntad produce los resultados que pretende.

Con todas las cautelas que merece el tema, quizá no cabe renunciar todavía totalmente a la razón en un intento de estudiar más a fondo los problemas que genera una nueva decisión o institución en el entramado institucional de nuestras sociedades.

Dejando bien claro que en muchas ocasiones las consecuencias que producen las decisiones son involuntarias -ni queridas ni previstas- y, poniendo de manifiesto el dilema que en el mundo de la responsabilidad se produce -se es responsable por lo que se quiere o por lo que se hace- tampoco cabe pasar de ahí al anarquismo legislativo, que podríamos enunciar del modo siguiente. Ya que es posible que las consecuencias difieran de los propósitos es igual cómo legislemos, puesto que no podremos controlar los resultados. Por tanto todo vale.

\section{Un modelo de cómo legislar}

Con el escepticimos moderado que sugiere lo dicho anteriormente, podemos formular un modelo constituido por un conjunto de preguntas que sirven para plantearse problemas. Es un conjunto de cuestiones que pueden ser difíciles de contestar, pero que sirven para tomar las decisiones con un conocimiento más profundo que el disponible. Que nadie confíe en recetas concluyentes. La decisión exige reflexión y ponderación de variables. Este modelo es una herramienta que sirve para mejorar la legislación si se aplica correctamente, pero no constituye ninguna receta para resolver los problemas. 


\section{La racionalidad lingüística}

Empecemos por la primera cuestión. Racionalizar la legislación supone racionalizar los mensajes. Podríamos hablar con M. Atienza de un conjunto de racionalidad entre las cuales la lingüística ocupa un lugar importante. Conservo el término racionalidad por fidelidad al modelo de Atienza aunque quizá sería mejor suavizar el término y hablar de cuestiones lingüísticas, lógico-formales, pragmáticas, teleológicas y éticas.

La ley se manifiesta en un lenguaje y éste debe comunicar al destinatario un mensaje claro. La reducción de la ambigüedad, vaguedad o redundancia del lenguaje es una condición de la racionalidad de la ley. Una ley bien hecha desde el punto de vista lingüístico ofrece mayor seguridad. Constituye una regla de juego que permite a los destinatarios saber a qué atenerse. Además liga a la autoridad y establece uno de sus límites públicos. Una ley es racional desde el punto de vista lingüístico si ofrece un mensaje y comunica al destinatario lo que pretende. La racionalidad lingüística de la ley no supone necesariamente una ausencia de tecnificación. No es necesario que el destinatario formal de la ley -por ejemplo la mayoría de los ciudadanos- sean capaces de entender el mensaje legislativo. Algunas leyes tienen como destinatarios mediatos a profesionales. Es evidente que la ley de presupuestos tiene unos tecnicismos que la convierten en ininteligible para la mayoría de los ciudadanos. Pero eso no significa que haya fracasado desde el punto de vista de la racionalidad lingüística porque bastaría que la comunicación fuera clara para los sectores profesionales que trabajan en ese tema.

Si nos preguntamos cuáles son las disciplinas que nos deben ayudar a la comunicación fluida veremos que no son estrictamente jurídicas. El auxilio de disciplinas como la lingüística, la lógica o la psicología cognitiva parece imprescindible.

La racionalidad lingüística es difícil de conseguir, puesto que las leyes se manifiestan en lenguajes débilmente tecnificados y precisamente son esquemas de interpretación de la conducta humana. En muchas ocasiones la irracionalidad lingüística se busca voluntariamente y eso no quiere decir que siempre que existe una irracionalidad lingüística constituya de por sí un disvalor. Esta racionalidad es independiente de la racionalidad ética.

Por último, la información es un elemento fundamental de valor y de desigualdad, y la manera cómo se transmite y quién es el destinatario supone asignar un recurso escaso que, según Hayek, ocupa un lugar tan importante como la división del trabajo. 


\section{La racionalidad lógico-formal.}

Un segundo nivel de racionalidad es el que denominaremos con Atienza lógico formal. A la pregunta si el mensaje comunica lo que pretende se le debe añadir una segunda. ¿Hasta qué punto este mensaje se integra en el sistema jurídico?

Concebimos el derecho como un sistema de normas, es decir, como un conjunto ordenado de normas que tiene unas características y propiedades determinadas. La inclusión de un nuevo elemento en este sistema, ¿produce contradicciones?, ¿deja supuestos sin regular? Este es un punto de vista especialmente importante para una buena legislación.

Los juristas han dedicado mucha atención a los problemas que sugiere la inserción de un nuevo elemento en el sistema jurídico. Han propuesto criterios que sirven para resolver antinomias y lagunas. Las diversas teorías de la interpretación normativas sugieren un elenco de criterios interpretativos, como el argumento de la coherencia, el a contrario, a simile y tantos otros que demuestran la preocupación por el problema. Ese es un tipo de racionalidad que los juristas han tenido especialmente en cuenta, aunque no se descarta la posibilidad de que otras disciplinas no jurídicas -como por ejemplo la lógica o la informática- puedan ser especialmente útiles para resolver problemas de coherencia. Pero no debemos olvidar que los juristas se han preocupado no como legisladores, sino como aplicadores del derecho y como descriptores del derecho. Los juristas han tenido que buscar el remedio a la irracionalidad del derecho. Aquí se trata de preguntarse desde el punto de vista del legislador. La racionalidad lógico formal trata de evitar que el ordenamiento jurídico se deteriore y se erosione tanto en el nivel de la contradicción entre sus normas como entre sus principios. La idea de que el ordenamiento jurídico está sustentado en una concepción institucional de la justicia juega también un papel de importancia, ya que los casos difíciles se deben resolver mediante esa estructura ordenada e íntegra de principios.

La teoría del derecho moderna se ha preocupado más por el problema de la coherencia y consistencia normativa que por la integridad valorativa. En los últimos años la creciente preocupación por el problema de la justificación de las decisiones ha tenido consecuencias importantes para el desarrollo de la racionalidad institucional de principios.

Por último cabría resaltar que la racionalidad formal es independiente de la racionalidad lingüística. Puede existir una ley que sea racional desde el punto de vista lingüístico pero que no lo sea desde el punto de vista formal. Puede existir una ley racional en los dos 
sentidos y también una irracional en los dos sentidos. En cambio parece ser que la falta de racionalidad lingüística -es decir si no se comunica bien o no se sabe qué comunicaimplicará dudas sobre su inserción en el sistema y por tanto consecuencias semejantes a la irracionalidad formal.

\section{La racionalidad pragmática}

La siguiente cuestión a plantear es la racionalidad pragmática. La pregunta que deberíamos contestar es la siguiente. ¿Hasta qué punto podemos conocer las reacciones de los ciudadanos? ¿Cómo van a reaccionar los ciudadanos frente a la ley? ¿Cuáles van a ser los efectos de las leyes? ¿Cómo afectan las leyes a la conducta social?

La cuestión es compleja porque las consecuencias no intencionales de las acciones son impredecibles. Las modernas corrientes de la elección racional han puesto de manifiesto que los efectos de nuestras decisiones no se corresponden necesariamente con nuestras intenciones y que en muchas ocasiones traicionan los valores y las metas que sostenemos. Es por tanto dudoso que esta pregunta se pueda responder mediante una teoría que ofrezca previsiones aseguradas. Ahora bien, si siguiéramos fielmente la tesis de la irracionalidad de las consecuencias, parece que deberíamos renunciar a cualquier tipo de previsión. Es, sin embargo, indudable que el plantearse como van a reaccionar los ciudadanos, o el presuponer que los hombres actúan por razones supone un avance. La vieja idea de que la voluntad del legislador puede cambiar el mundo está en crisis. En el otro extremo se encuentra la idea de la imprevisibilidad, tesis que es parcialmente verdadera pero que no vacía de sentido al intento de preguntarse por la reacción de los ciudadanos.

Una vez mostradas las cautelas con las que debemos plantear la cuestión es importante tener en cuenta que existen disciplinas que tratan de estudiar la conducta social y que éstas pueden ser de especial utilidad a la hora de prever cuál va a ser la reacción de los destinatarios de las normas -y también- para detectar hasta qué punto los ciudadanos adecuan la conducta a la norma. En los trabajos de ciencia y técnica legislativa éste es un elemento que se enuncia, pero que poco a poco su importancia se diluye en el discurso. $\mathrm{O}$ bien se confía excesivamente en el papel de una futura sociología o bien se supravalora los resultados intencionales frente a las consecuencias en la conducta social. Quizá el planteamiento cabría revertirlo. Una ley que no consigue una amplia adhesión demostrada en conducta social tiene un grave defecto de diseño. Lo importante de las leyes no es lo que dicen, sino lo que hacen. Un excesivo valor simbólico 
del derecho produce necesariamente un incentivo a no tomarse el derecho en serio y a socavar las razones que lo justifican.

La racionalidad pragmática supone que la ley consigue el objetivo que pretende. Para lograr eso es necesario plantearse, pensar y analizar cuál va a ser la reacción de los ciudadanos, simular cuál sería la reacción de los ciudadanos si se modificara en algún sentido la medida. Por supuesto que eso sólo se puede conseguir en un cierto grado. Simplemente quisiera señalar que usualmente los juristas no se plantean este problema. Tampoco acostumbran a tener los recursos materiales y humanos a su alcance.

Una ley es irracional en el sentido pragmático cuando no consigue que la conducta social se ajuste a la ley. Una ley que se viola frecuentemente -aunque se aplique la sancióntiene un defecto de diseño. Carece de racionalidad pragmática.

\section{La racionalidad teleológica}

La siguiente racionalidad es la teleológica. El derecho puede verse como un medio que tiende hacia una finalidad. Para llegar a un objetivo determinado es necesario asignar los recursos de una forma óptima. Las leyes no sólo deben ofrecer incentivos a los ciudadanos para su cumplimiento, sino que además es necesario que se consiga el objetivo con el mínimo costo. Disciplinas como la teoría económica y especialmente el análisis económico del derecho han dado especial relevancia a la perspectiva de la relación entre medios y fines. Sin duda ése es un problema importante. Una ley bien hecha desde el punto de vista de la racionalidad teleológica es aquella que consigue su objetivo con el mínimo costo. Hay quien ha puesto tanto énfasis en la eficiencia -entendida como mínimo costo social- que ha sustituido el concepto de justicia por el concepto de eficiencia. En realidad la preocupación por la producción de bienes y servicios no puede ser considerada de una forma independiente de la distribución. Una sociedad bien diseñada no es aquella que distribuye conforme un buen diseño -es decir conforme a un plan justo-, sino aquella en la cual el plan además de ser justo, se cumple.

Para que exista distribución es preciso que exista producción. En muchos casos se produce una relación inversa entre producción y distribución y, por tanto, deberíamos hablar del equilibrio entre los valores de eficiencia y equidad y dejar en un segundo plano la prioridad de la producción o de la distribución. Una ley es irracional desde el punto de vista de la racionalidad teleológica si asigna ineficientemente los recursos. Pero no hemos de olvidar que el despilfarro de recursos públicos también es un problema ético. El funcionario 
injustificadamente ineficiente incumple con la moral porque debe asignar óptimamente los recursos públicos.

\section{La racionalidad ética}

De una forma imperceptible de la racionalidad teleológica hemos pasado a la racionalidad ética. Una ley es éticamente racional si concuerda con un determinado código o punto de vista ético. Si eso es cierto entonces la ley será legítima. La racionalidad ética supone la justificación última de la conducta, de la acción o de la ley. Sin embargo, vale aquí lo mismo que dijimos en otras ocasiones. Lo importante de una ley no es la declaración de principios que ofrece sino lo que consigue. Una ley muy excelsa éticamente pero que no se cumple no es una buena ley. Puede tener una racionalidad ética pero si no se cumple, si no se obedece, no consigue su objetivo fundamental. Puede estar legitimada desde cualquier punto de vista pero carece de suficiente fuerza como para regir la conducta humana. La función de un legislador no es hacer declaraciones de principios, sino dirigir la conducta y garantizar derechos. En el modelo de Atienza se afirma que la racionalidad ética es el fin y las otras racionalidades son instrumentales. Sin embargo, creo que esos instrumentos son componentes de la racionalidad ética porque un muy buen diseño ético de una ley no produce una buena ley. Lo que consigue la ley es el criterio fundamental.

El cumplimiento y la obediencia de la ley no depende sólo de la motivación ética. En un mundo de kantianos que obran conforme a los principios morales quizá podría ser el único criterio de legislación, sin embargo estos kantianos deberían enfrentarse con el problema de las consecuencias no intencionadas de la ley y se despreciarían todas aquellas racionalidades que no fueran las estrictamente ética. Mi posición es que la ética debe dirigir la conducta humana pero que la ética no debe convertirse en un conjunto de principios interesantes para la teoría pero incapaces de resolver los problemas en la práctica.

Esa es una buena recomendación para aquel que se plantea el problema del diseño de instrumentos jurídicos. La intuición de la bondad ética de un principio es un elemento fundamental, es la luz que ilumina el camino y nos indica hacia dónde debemos ir, pero no nos resuelve el problema. Debemos formulamos otras cuestiones precisamente para poder salvaguardar mejor esos principios éticos. El dilema weberiano continúa planteándose. El legislador ¿debe actuar conforme a los principios o a las consecuencias? El político, el técnico legislativo tiene una luz -las convicciones-. Éstas no 
son declaraciones de principios, sino que deben juzgarse en función de lo que realmente consiguen. Para conseguir ese objetivo se deben resolver algunos problemas difíciles. ¿Nos guiamos por las convicciones o por las consecuencias?, ¿por las convicciones pero implementadas por algo más que por la declaración o su realización? Y, entonces, el análisis de las consecuencias, los costos, los medios, la previsión tentativa de las conductas, las sanciones o los incentivos que se deben ofrecer son preguntas que exigen alguna respuesta y que sirven también para justificar por qué la ley es cómo es. Y en este sentido sí que podemos predicar una mayor racionalidad de la ley.

\section{Algunas reflexiones sobre el modelo de Atienza}

Hasta aquí he seguido -con algunas pequeñas variantes- el modelo que propone Atienza que me parece en líneas generales muy acertado y que constituye un punto de partida excelente para reflexionar. Sin embargo, también se habrá podido observar que en algunos puntos existen diferencias. Éstas serían las más importantes.

1. Atienza sugiere hablar de racionalidad. Creo que el término racionalidad complica las cosas por su ambigüedad y vaguedad. Sería preferible renunciar a esa palabra y enfocar la cuestión sin necesidad de tenerse que aclarar respecto a lo que significa racionalidad y sus funciones ideológicas. En realidad su modelo constituye una herramienta conceptual que podría ser usada para fines muy diversos -conservadores o no. El valor de su planteamiento reside sobre todo en que ofrece preguntas para reflexionar. No es un recetario de racionalidad, sino un instrumento que permite a quien lo utilice decidir con mayor conocimiento de causa.

La cuestión no sólo es terminológica, sino que el desacuerdo también es de fondo. Atienza pretende reconstruir la racionalidad legislativa, pero lo hace desvinculando las racionalidades unas de otras. No es muy adecuado hablar de legislación racional en un sentido y no en otro. Tampoco estoy muy convencido de que se puedan separar en compartimentos estancos la racionalidad teleológica y la ética por ejemplo. Sobre este punto volveré más adelante.

Me parece que su modelo es mucho más útil viéndolo como un instrumento y no como una reconstrucción de la racionalidad legislativa en mayúscula.

2. Una cuestión -que al hilo de la lectura del texto ya ha surgido- es el tratamiento -o mejor el no tratamiento- de las consecuencias 
involuntarias de nuestras decisiones. Me parece que debería ofrecer una respuesta desde el modelo a los planteamientos de la teoría de la elección racional y al problema de la racionalidad colectiva. Creo que el planteamiento de Atienza es demasiado voluntarista porque establece un nexo muy directo entre legislación, intención, bondad ética y resultado. El presupuesto subyacente es que la decisión colectiva y la decisión individual están íntimamente relacionadas. La intención y el resultado tienen un nexo que es fundamental y por esta razón la racionalidad ética ocupa un lugar privilegiado en el modelo. Me parece que desde el punto de vista del legislador lo más importante es el resultado que obtiene y no la intención. El valor ejemplar de las declaraciones es inferior a la conducta real. Por otra parte todas sus argumentaciones sobre el valor simbólico parece que ignoran las consecuencias no intencionadas de las decisiones humanas. El defecto fundamental de quien legisla es su creencia implícita -no meditada ni reflexionada- de que si la ley es buena éticamente, y la autoridad que la dicta es legítima entonces los destinatarios la tomarán en cuenta como razón excluyente para actuar. Eso no es cierto. Los ciudadanos toman las leyes como un dato y no como la razón para actuar.

En síntesis el modelo de Atienza todavía concede mucho valor a lo que declara la ley y no tanto a lo que consigue. Es cierto que señala el problema y que uno de sus grandes méritos ha sido introducir dudas acerca del modelo tradicional según el cual con la racionalidad ética se tenía suficiente criterio para legislar. Mi desacuerdo reside en el criterio de valoración de lo que hace el legislador. Prefiero juzgar por lo que hace más que por lo que dice. Más vale una conducta que mil palabras.

Por otra parte el presupuesto de que las decisiones individuales -intención del que legisla- produce resultados que son racionales desde el punto de vista de la racionalidad colectiva se ha puesto en duda y se conocen demasiados contraejemplos para continuar manteniendo esta tesis. Dicho sea de pasada las cuestiones del diálogo racional y del consenso ideal se verían afectados también por el problema puesto que es posible que se produjeran consecuencias involuntarias debidas a la estructura de la interacción. Las paradojas del liberalismo señaladas por ejemplo por Sen serían obstáculos a salvar.

3.Otro desacuerdo -quizá más profundo- se encuentran en la concepción de una sociedad bien ordenada. Atienza se plantea el problema como si la producción y la distribución de bienes fueran independientes. Tengo la convicción de que una sociedad justa no es la que distribuye mucho ni la que produce, sino la que desarrolla un determinado equilibrio entre producción y distribución. Y ese equilibrio 
no está desarrollado en unos papeles ni en una carta de navegación meramente teórica, sino que también está decidido en la práctica. En el fondo dibujar una sociedad justa no es otra cosa que asignar recursos escasos para conseguir unos fines y priorizar entre ellos. Nosotros podemos saber cómo se priorizan en nuestra sociedad por ejemplo los derechos a la vida. $\mathrm{Si}$ acudimos al derecho veremos que todos tenemos el derecho a la vida. Pero si analizamos qué recursos se dedican a garantizar el derecho a la vida nos daremos cuenta que ésta es otra historia y que en nuestras sociedades se decide sobre la vida asignando recursos a la prevención de accidentes, a la de enfermedades, a la muerte, etc. En la práctica se prioriza y se decide sobre la vida. Decidir significa priorizar recursos escasos y toda política los prioriza. El campo de discusión no está tanto en la declaración como en la prioridad. No niego la importancia de la declaración, pero una vez alcanzada es necesario ir más allá y construir modelos justificatorios de las prioridades. Si se acepta este argumento entonces parece que la asignación de recursos y su distribución no se pueden separar, que la racionalidad económica y la racionalidad ética no se pueden dar por separado, sino que se deben dar conjuntamente y que por tanto la compartimentación de la racionalidad no es posible.

Estas tres primeras constituyen reflexiones de fondo junto a ellas quisiera señalar algunos detalles.

1. Atienza sostiene, con razón, que cuando se plantean temas de racionalidad teleológica el análisis económico del derecho juega un papel fundamental aunque muestra cautelas ante el neoliberalismo de la escuela de Chicago. Creo que no hay un sólo análisis económico del derecho y que junto a posiciones que identifican la justicia con la eficiencia (Posner) podemos encontrar posiciones más matizadas y aceptables como las de Calabresi. El análisis económico del derecho es un instrumento que se puede utilizar para fines muy diversos. Una legislación fiscal eficiente no está reñida con una legislación fiscal progresiva.

Por otra parte el mismo concepto de eficiencia tiene significados distintos. No es lo mismo un óptimo paretiano, que la mayor riqueza social o el mínimo coste social. Posner ha dedicado parte de su libro Economics of Justice a diferenciar su concepto de eficiencia de conceptos utilitaristas. Hay muchas maneras de asignar los medios para conseguir fines. Mi tesis es que quien dispone de recursos públicos ineficientemente, quien despilfarra recursos sin razones no actúa moralmente.

2. Respecto a la racionalidad lógico formal debería señalarse que los juristas no tienen modelos de cómo legislar sin contradicciones. Ahora bien, los juristas se encuentran con los problemas de 
interpretación y de aplicación y tienen técnicas que sirven para resolver los problemas que los legisladores han dejado irresueltos. Enfocan los problemas de legislación con una red conceptual creada para aplicar el derecho. La perspectiva es muy distinta. Deberían pensarse modelos para prevenir los problemas y después usar el conocimiento jurídico para resolverlos.

Atienza señala que los juristas se preocupan de legislar. Eso es cierto, pero su aparato conceptual está diseñado para aplicar y no para crear derecho. Los juristas de vacaciones crean derecho. Carecen de una red conceptual elaborada para realizar esta tarea y en este sentido creo que es necesario matizar su tesis. Los juristas cuando legislan no tienen instrumentos tan depurados como cuando aplican el derecho. La intuición ocupa un lugar mucho más importante. La idea de sujeción a la ley es un instrumento inadecuado para legislar mientras que no se usan modelos de coherencia e integridad institucional que serían los adecuados para llevar a cabo la tarea legislativa.

3. Estoy de acuerdo con Atienza que la distinción entre creación y aplicación del derecho no debe ser absoluta. Las nuevas redes conceptuales creadas para la legislación se podrían usar en otras parcelas jurídicas. Creo que el modelo de Atienza no sólo sería útil en el nivel legislativo, sino también en el diseño de decisiones judiciales y resoluciones administrativas. Me parece que el tipo de preguntas que formula al legislador se las podría hacer el juez o el funcionario administrativo. Es probable que el derecho mejorara en calidad.

Pero creo que los temas de legislación no se pueden plantear sin tener en cuenta el problema de la legislación desde un punto de vista global. Una nueva ley exige la asignación de recursos y éstos son siempre escasos. Los efectos que tiene la ley no es sólo sobre la conducta, sino también sobre la asignación de otros recursos para implementar otras leyes. Los juristas cuando privilegiamos la racionalidad ética estamos comparando el contenido de la ley con un ideal ético pero en un mundo real se debe priorizar entre diversos contenidos éticos posibles. La objeción sería más global si dijéramos que la racionalidad ética es negativa. Nos indica cuál es la ley que no puede dictarse. Nos indica cuál es la injusta. Pero ¿cómo decidimos entre diversos ideales éticos? Mi argumento es que nuestras sociedades deciden y priorizan y que esta decisión no es independiente de los recursos. Los derechos no son aspiraciones sino garantías.

\section{A modo de conclusión}

Inicié este trabajo preguntándome por qué no existía una ciencia de la legislación en nuestras latitudes hasta épocas muy recientes. La 
respuesta se encuentra en la insuficiencia de la red conceptual jurídica tradicional para resolver este problema. Sólo adoptando un punto de vista diferente es posible desarrollar esta disciplina y resolver el problema de la inadecuación de la mentalidad y la formación del funcionario para la tarea que se le asigna. Luego nos hemos planteado qué preguntas deberíamos formular para dictar una ley bien hecha. La respuesta ha exigido la construcción de un modelo muy sencillo de preguntas -sugerido por Atienza- centrado en la racionalidad lingüística, formal, pragmática, teleológica y ética. Ante una nueva ley podemos preguntarnos si comunica al destinatario el mensaje, si ése se inserta en el sistema jurídico sin contradicciones, si los ciudadanos lo van a cumplir, si se tienen los recursos económicos y humanos y si se asignan correctamente y, por último, si está justificada éticamente. El modelo de Atienza apunta a cuestiones importantes. Pero creo que no tiene en cuenta los aspectos de las consecuencias involuntarias de las decisiones legislativas y es demasiado optimista respecto al voluntarismo. En segundo lugar, desvincula demasiado la racionalidad ética de las demás racionalidades. Si preguntamos sobre la excelencia ética de las leyes sin tener en cuenta los recursos, me parece que desenfocamos el problema. En un mundo de recursos escasos, las leyes establecen prioridades entre objetivos. Una buena ley no debe juzgarse por su excelencia declarada, sino por la excelencia que consigue. Y, no todas las excelencias pueden conseguirse. Por supuesto que este modelo sugiere muchos más problemas, pero sin duda el producto -la ley- tiene más probabilidades de estar bien hecho si pasa los test de racionalidad. Creo que sería un buen ejercicio acudir con estas preguntas a la legislación española y analizar hasta qué punto pasa con nota los diversos tests de racionalidad.

Y para acabar quisiera aclarar que ese modelo es sólo una herramienta de trabajo que exige una mentalidad abierta hacia otras disciplinas que intervienen como materiales de construcción de las decisiones públicas. No se trata de convertir a los juristas en economistas, éticos, informáticos o lingüistas, sino de propiciar la suficiente sensibilidad para trabajar en equipo y poder formular las cuestiones pertinentes para diseñar leyes mejores.

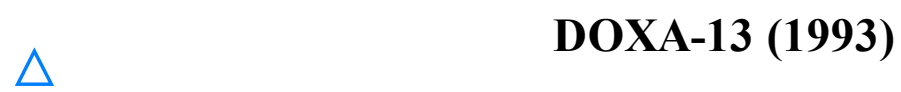

